\title{
Charles Moureu : du Collège de France aux gaz de combat
}

\section{Marc Fontecave}

\section{(2) OpenEdition}

12 Journals

Édition électronique

URL : https://journals.openedition.org/lettre-cdf/3054

DOI : $10.4000 /$ lettre-cdf.3054

ISSN : 2109-9219

Traduction(s) :

Charles Moureu: From the Collège de France to poison gases - URL : https://journals.openedition.org/ lettre-cdf/2198 [en]

\section{Éditeur}

Collège de France

Édition imprimée

Date de publication : 1 mars 2015

Pagination : 16-17

ISSN : 1628-2329

\section{Référence électronique}

Marc Fontecave, "Charles Moureu : du Collège de France aux gaz de combat », La lettre du Collège de France [En ligne], 39 | mars 2015, mis en ligne le 26 novembre 2015, consulté le 17 août 2022. URL : http://journals.openedition.org/lettre-cdf/3054 ; DOI : https://doi.org/10.4000/lettre-cdf.3054 


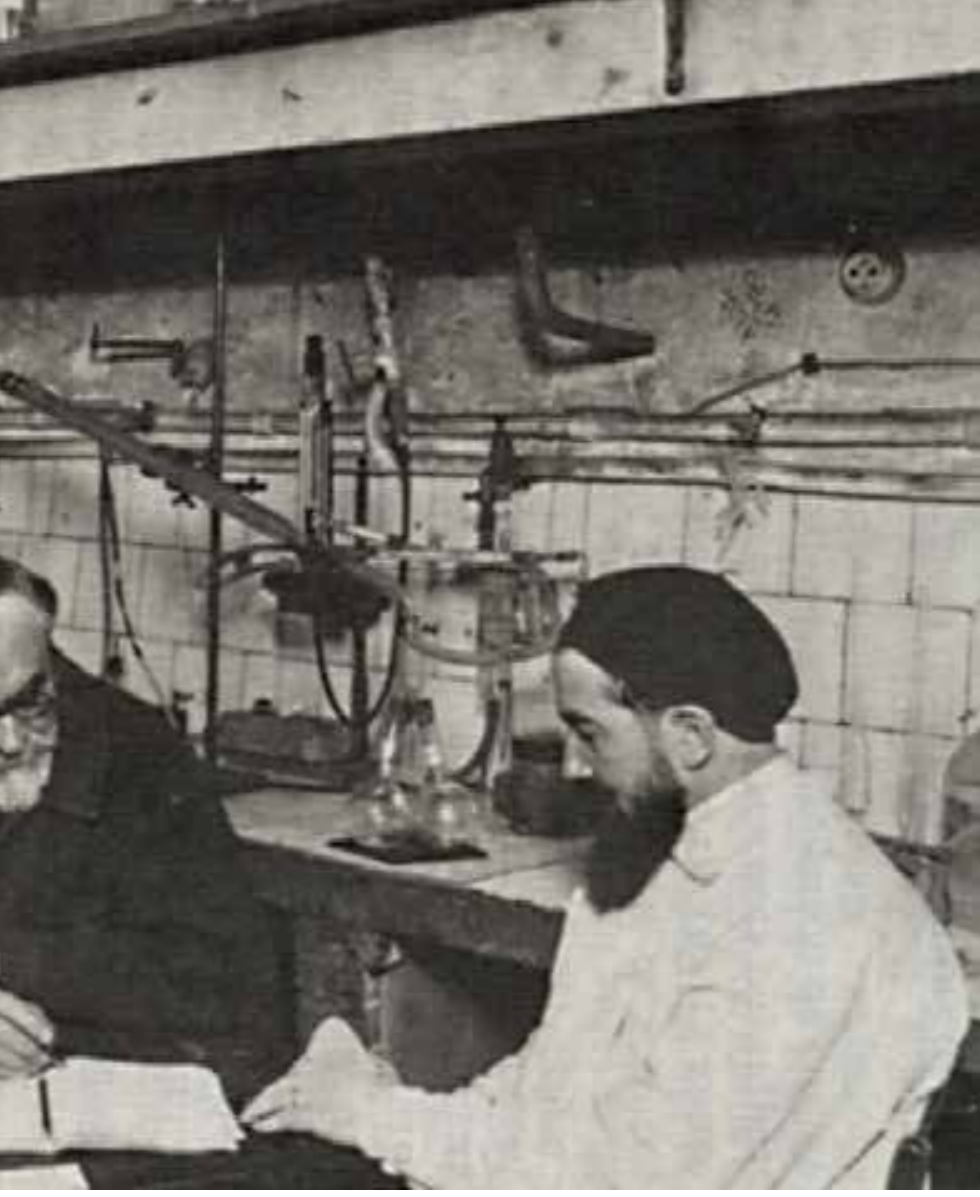

doute la plus marquante de ses découvertes, à savoir celle des antioxydants, nomination actuelle pour ce que Moureu à l'époque désignait comme des " antioxygènes ».

Cette découverte aurait certainement mérité le prix Nobel si, comme on l'a déjà dit, l'œuvre de Moureu n'avait pas été entachée du sang des soldats asphyxiés par ses molécules élaborées en temps de guerre. Ces antioxydants sont aujourd'hui utilisés à grande échelle comme agents de conservation et pour ralentir le vieillissement, c'est-à-dire l'oxydation, des molécules et des matériaux, dans l'industrie chimique, dans l'industrie alimentaire ou dans les cosmétiques. De nombreux médicaments sont utilisés pour leurs propriétés antioxydantes.

Les organismes vivants eux-mêmes ont élaboré des mécanismes complexes de régulation antioxydante qui leur permettent de vivre dans l'atmosphère oxygénée de la terre et des molécules spécifiquement antioxydantes, comme la vitamine $\mathrm{C}$, ou la vitamine $\mathrm{E}$ ou l'ubiquinone, un antioxydant membranaire sur lequel nous travaillons aujourd'hui dans mon laboratoire. Des armes chimiques aux antioxydants, on voit bien à nouveau tout le paradoxe de la science et de ce qu'en font les hommes.

Extraits de la communication prononcée par le Pr Marc Fontecave

Retrouvez en ligne l'intégralité de cette intervention sur le site Internet du Collège de France : www.college-de-france.fr/site/colloque-2014/ symposium-2014-10-16-14h00.htm
Dans leur laboratoire parisien,

les professeurs Charles Moureu

et Charles Dufraisse, DR

Interventions $d u$ colloque de rentrée consultables en ligne

\section{Ouverture}

Serge Haroche, Collège de France

Vienna before 1914 and after 1918: Continuities and Breaks

\section{Anton Zeilinger, Université de Vienne}

Berlin après 1918 : une modernité problématique Céline Trautmann-Waller, Université Paris 3 Sorbonne Nouvelle

Les conséquences de la guerre pour la vie universitaire en Europe

Jürgen von Ungern-Sternberg, Université de Bâle

Orientalistes : aventuriers, experts et diplomates Henry Laurens, Collège de France

Charles Moureu : du Collège de France aux gaz de combat

Marc Fontecave, Collège de France

Un tournant dans les rapports entre mathématiques et physique

Françoise Balibar, Université Paris 7 Diderot

Guerre, littérature et démocratie

Antoine Compagnon, Collège de France

Le langage, la logique et la philosophie Jacques Bouveresse, Collège de France

Les philosophes français face à la guerre : politique, morale, philosophie

\section{Claudine Tiercelin, Collège de France}

Picasso, Duchamp, Kandinsky : I'atelier du XXe siècle Roland Recht, Collège de France

Guerre et cinéma sous la République de Weimar Olivier Agard, Université Paris 4 Sorbonne

Ruptures musicales superficielles et profondes Makis Solomos, Université Paris 8 Vincennes

L'émergence de la psychanalyse : un fait de civilisation? Roland Gori, Université d'Aix-Marseille

Un effet Grande Guerre sur la psychiatrie française? Isabelle von Buelzingsloewen, Université Lyon 2 Lumière

Guerres et construction de l'État : l'exemple de l'éducation

Philippe Aghion, Université Harvard

Le chef : étude transnationale d'un objet partagé Yves Cohen, EHESS

La guerre a bouleversé I'amour

Michelle Perrot, Université Paris 7 Diderot
Pr Marc FONTECAVE

Chimie des processus biologiques 